\title{
VILLANDI-LAHEKULA LEIUKOHTADE DIKTÜONEEMAKILDA OMADUSTEST JA KEEMILISEST KOOSTISEST
}

Artikkel on lühikokkuvõte uurimistöödest, mille tegi Keemia Instituudi rikastusprotsesside sektor Villandi-Laheküla leiukohtade diktüoneemakilda mōnede geokeemiliste omaduste ja makro- ning mikrokomponentse koostise selgitamiseks 1960. aastatel. Uurimiseks saadi puursüdamikud Eesti NSV Geoloogia Valitsuselt. Praegune kirjutis on jätk varem avaldatud artikleile $\left[{ }^{1-5}\right]$.

Uurimistöödeks oli kasutada 12 puursüdamikku (36 proovi) VillandiLaheküla leiukohtadest, mille ulatus läänest itta oli $34 \mathrm{~km}$. Leiukohtade paremaks iseloomustamiseks puuriti nagu varemgi niihästi lääne-idakui ka põhja-ida-suunaliselt. Mikrokomponentidest määrati 9 elemendi - titaani, vanaadiumi, nikli, koobalti, vase, tsingi, plii, molübdeeni ja indiumi kontsentratsioon. Makrokomponentidest määrati orgaanilise aine, püriitväävli (ka püriidi), räni $\left(\mathrm{SiO}_{2}\right.$ kujul), alumiiniumi, kaaliumi, kaltsiumi, magneesiumi ja raua sisaldused (tab. 1).

Ränidioksiidi, alumiiniumi, kaaliumi, kaltsiumi, magneesiumi ja raua sisaldus määrati klassikalise kvantitatiivse analüüsi meetodeil [ ${ }^{6}$. Hajutatud ja haruldaste elementide sisaldus määrati varem kasutatud meetodeil [5]. Uuena esineb indium, mille kontsentratsioon määrati polarograafiliselt. Indiumi esinemist Eesti NSV päritoluga püriidi kristallides on uurinud H. Palmre $\left[{ }^{7}\right]$.

Orgaaniline aine. Orgaanilise aine sisalduse määramiseks diktüoneemakildas kasutati O. Kirreti, R. Kochi ja L. Ründali valemit [5]. VillandiLaheküla leiukoha diktüoneemakildas on orgaanilise aine keskmine sisaldus $11.48 \%$.

Põlemisväärtus. Villandi-Laheküla leiukohtade diktüoneemakilda põlemisväärtus varieerub $766-1143 \mathrm{kcal}$ kilogrammi kohta. Leiukoha keskmine on $962.5 \mathrm{kcal} / \mathrm{kg}$.

Väävel. Püriidi tekkeloost. Diktüoneemakildas esinevad järgmised seotud väävli liigid: sulfiid- (metallsulfiidid ja püriit, keemilise nimetusega raudpersulfiid), sulfaat- ja orgaaniline väävel. Püriit- ehk raudpersulfiidväävli sisaldus on toodud tabelis 1 ja 2 , teiste väävliliikide sisaldus tabelis 2.

Varasemates töödes $\left[^{1-5}\right]$ ei arvestatud plii, vase, koobalti, mangaani, nikli, tsingi, vanaadiumi ja molübdeeniga seotud väävlit, kuna puudusid andmed nimetatud ainete sisalduse kohta kildas.

Diktüoneemakilda üldväävel määrati Eschka meetodil. Sulfaatse ja püriitse väävli määramiseks kasutati B. Torpani poolt modifitseeritud Powell-Parri meetodit. Metallsulfiidide määramiseks arvutati hajutatud ja haruldaste metallidega $(\mathrm{Ni}, \mathrm{Cu}, \mathrm{Zn}, \mathrm{Pb}, \mathrm{V}, \mathrm{Mo})$ seotud sulfiidse väävli hulk. Orgaanilise ainega seotud väävli kogus arvutati üldväävlist püriitse (raudpersulfiidse) + metallsulfiidse + sulfaatse väävli lahutamisega.

Villandi-Laheküla leiukohtade diktüoneemakilda keskmiseks väävlisisalduseks leiti $4.57 \%$. Tabelis 2 on toodud erinevate väävliliikide esinemine Villandi-Laheküla leiukohtade diktüoneemakildas, milles kõige enam on püriitväävlit, järgneb sulfaat-, orgaaniliselt seotud väävel ning haruldaste ja hajutatud metallidega seotud metallsulfiidväävel. Kuna keskkond oli $\mathrm{H}_{2} \mathrm{~S}$ tōttu taandav, siis on kindel, et rida lahuseis olevaid 
Villandi-Laheküla leiukohtade diktüoneemakilda omadustest

\begin{tabular}{|c|c|c|c|c|c|c|c|}
\hline \multirow{2}{*}{$\begin{array}{l}\text { Puur- } \\
\text { augu } \\
\text { nr. }\end{array}$} & \multirow{2}{*}{$\begin{array}{c}\text { Puurimis- } \\
\text { sügavus } \\
\text { m }\end{array}$} & \multirow{2}{*}{$\begin{array}{l}\text { Puur- } \\
\text { süda- } \\
\text { miku } \\
\text { paksus } \\
\text { m }\end{array}$} & \multirow{2}{*}{$\begin{array}{c}\text { Põle- } \\
\text { mis- } \\
\text { väär- } \\
\text { tus } \\
\mathrm{Q} \\
\mathrm{kcal} / \mathrm{kg}\end{array}$} & \multicolumn{4}{|c|}{$\%$} \\
\hline & & & & $\begin{array}{c}\text { Orgaa- } \\
\text { niline } \\
\text { aine }\end{array}$ & Püriitväävel & $\mathrm{SiO}_{2}$ & $\mathrm{Al}$ \\
\hline 79 & $14.20-17.00$ & 2.80 & 868 & 10.39 & $3.92(8.47)^{*}$ & - & 4.94 \\
\hline 93 & $10.60-12.70$ & 2.10 & 963 & 11.53 & $2.39(5.14)$ & 55.75 & 5.67 \\
\hline 84 & $15.35-17.40$ & 2.05 & 834 & 9.99 & $4.02(8.65)$ & 54.73 & 5.47 \\
\hline 99 & $24.35-26.40$ & 2.05 & 1065 & 12.76 & $3.66(7.90)$ & 55.71 & 5.98 \\
\hline 101 & $24.90-26.80$ & 1.90 & 1106 & 13.25 & $2.54(5.49)$ & 52.74 & 6.66 \\
\hline 103 & $18.10-20.30$ & 2.20 & 969 & 11.61 & $3.18(6.87)$ & - & 5.26 \\
\hline 113 & $17.25-19.00$ & 1.75 & 1143 & 13.16 & 3.54 (7.65) & 50.93 & 5.15 \\
\hline 107 & $14.80-16.40$ & 1.60 & 841 & 10.07 & $1.00(2.16)$ & - & 4.56 \\
\hline 133 & $11.70-12.80$ & 1.10 & 956 & 11.45 & $4.50(9.68)$ & - & 4.62 \\
\hline 119 & $18.00-19.90$ & 1.90 & 766 & 9.17 & $3.70(7.99)$ & - & 4.73 \\
\hline 123 & $19.20-20.25$ & 1.05 & 1070 & 12.81 & $4.84(10.45)$ & - & 4.62 \\
\hline 131 & $18.50-19.65$ & 1.15 & 969 & 11.61 & $2.69(5.81)$ & - & 4.93 \\
\hline Keskm & & 1.80 & 962.50 & 11.48 & $3.33(7.18)$ & 53.97 & 5.21 \\
\hline
\end{tabular}

* Püriit protsentides.

metallioone oli madalamas oksüdatsiooniastmes, järelikult sadestusid mere mudavetes, kus lahuse $\mathrm{pH}$ oli suurem kui $8, \mathrm{PbS}, \mathrm{CuS}, \mathrm{NiS}, \mathrm{CoS}$, $\mathrm{V}_{2} \mathrm{~S}_{3}, \mathrm{MoS}_{2}$, tõenäoliselt ka $\mathrm{MnS}$.

Seoses väävli eri liikidega väärib tähelepanu püriidi kui mineraali ehk keemilise ühendi raudpersulfiidi, nomenklatuurse nimetusega rauddisulfiidi $\mathrm{Fe} \int_{\mathrm{S}}^{\mathrm{S}}$ tekkeprobleem, millest lühidalt järgnevas.

Reaktsioonivõimelise raua all mõistetakse $\mathrm{Fe}^{3+}$ ühenditena merre suubunud oksiide, hüdroksiide $\mathrm{FeOOH}$ või oksiidhüdraate $\mathrm{Fe}_{2} \mathrm{O}_{3} \cdot \mathrm{H}_{2} \mathrm{O}$ ja $\mathrm{Fe}^{2+}$ ühendeid ning väga vähesel hulgal esinevat $\mathrm{FeS}\left[{ }^{8}\right]$.

Meres bakteriaalse sulfaatreduktsiooni tagajärjel tekkinud divesiniksulfiidi reageerimisel reaktsioonivõimelise rauaga viiakse viimane kolloidse raudmonosulfiidina (FeS-ina) mudavee setetesse. Moodustunud mineraal on tuntud hüdrotroiliidina. Selle koostisvalem on $\mathrm{FeS} \cdot \mathrm{nH}_{2} \mathrm{~S}$ või $\mathrm{FeS} \cdot \mathrm{nH}_{2} \mathrm{O}[9,10,11,12]$.

On avastatud veel rida kristallstruktuurilt erinevaid raudsulfiidmineraale. Hüdrotroiliite tuleb pidada lähteaineks amorfse kolloidse loomuga kristalsetele sulfiididele (makkinoviit, kansiit, greigiit). Neist makkinoviiti on leitud sulfiidide koostises praegusaja setetes [ $\left.{ }^{8}\right]$.

On tehtud mitmeid ettepanekuid reaktsioonimehhanismide kohta, et seletada ookeani mudavetes tekkinud $\mathrm{FeS}$-i püriidistumist elementaarse väävli $\mathrm{S}^{0}$ osavōtul vesilahuseis püriidiks ehk keemiliseks ühendiks raudpersulfiidiks $\mathrm{FeS}_{2}$. Esimene reaktsioon arvatakse kulgevat tiosulfaadi kui elementväävli ülekandja osavõtul [ $\left.{ }^{8}\right]$ :

$$
\begin{gathered}
\mathrm{FeS}+\mathrm{S}_{2} \mathrm{O}_{3}^{2-} \longrightarrow \mathrm{FeS}_{2}+\mathrm{SO}_{3}^{2-} \\
\mathrm{SO}_{3}^{2-}+\mathrm{S}^{0} \longrightarrow \mathrm{S}_{2} \mathrm{O}_{3}^{2-} .
\end{gathered}
$$

Teine reaktsioon kulgevat disulfaani $\mathrm{H}_{2} \mathrm{~S}_{2}$ osalusel [ $\left.{ }^{13}\right]$ :

$$
\mathrm{H}_{2} \mathrm{~S}+\mathrm{S}^{0} \longrightarrow \mathrm{H}_{2} \mathrm{~S}_{2}
$$

$\mathrm{FeS}+\mathrm{H}_{2} \mathrm{~S}_{2} \longrightarrow \mathrm{FeS}_{2}+\mathrm{H}_{2} \mathrm{~S}$.

Kolmas reaktsioon toimuvat polüsulfiidioonide $\mathrm{S}_{4} \mathrm{~S}^{2-}$ ja $\mathrm{S}_{5} \mathrm{~S}^{2-1}$ osavõtul [14]. Püriidistumise reaktsioon näeb välja järgmine: 
ja keemilisest koostisest arvutatuna absoluutkuivale ainele

\begin{tabular}{|c|c|c|c|c|c|c|c|c|c|c|c|c|}
\hline $\mathrm{K}$ & $\mathrm{Ca}$ & $\mathrm{Mg}$ & $\mathrm{Fe}$ & $\mathrm{Ti}$ & V & Co & $\mathrm{Ni}$ & $\mathrm{Cu}$ & $\mathrm{Zn}$ & $\mathrm{Pb}$ & Mo & In \\
\hline - & 0.73 & - & 431 & 2900 & 399 & & 86 & 9? & 243 & 307 & 263 & 60 \\
\hline 5.41 & 0.64 & 0.42 & 4.14 & 3375 & 269 & & 54 & 68 & $\begin{array}{l}245 \\
190\end{array}$ & 190 & $\begin{array}{l}200 \\
323\end{array}$ & $\begin{array}{l}0.0 \\
4.8\end{array}$ \\
\hline 4.77 & 0.67 & 0.30 & 5.31 & 3723 & 348 & & 84 & 87 & 144 & 108 & 254 & 4.5 \\
\hline 5.18 & 0.66 & 0.42 & 4.94 & 3872 & 367 & & 57 & 54 & 195 & 280 & 269 & 5.4 \\
\hline 5.28 & 0.75 & 0.24 & 4.33 & 3905 & 499 & & 67 & 71 & 133 & 414 & 423 & 5.0 \\
\hline & 0.63 & - & 4.40 & 3723 & 215 & 13.0 & 141 & 86 & 362 & 150 & 377 & 5.4 \\
\hline 4.76 & 0.86 & 0.25 & 5.07 & 3535 & 554 & & 58 & 78 & 124 & 366 & 472 & 4.7 \\
\hline & 0.69 & - & 3.57 & 3381 & 544 & & 58 & 58 & 186 & 193 & 404 & 4.6 \\
\hline & 0.70 & & 4.23 & 2895 & 463 & & 75 & 59 & 513 & 197 & 427 & 5.3 \\
\hline & & & 374 & 2784 & 441 & & 86 & 65 & 164 & 167 & 548 & 5.9 \\
\hline & & & 4.26 & 2900 & 410 & & 114 & 60 & 364 & 203 & 510 & 6.1 \\
\hline & & & 3.78 & 3096 & 394 & & 100 & 69 & 328 & 156 & 587 & 4.4 \\
\hline 5.08 & 0.70 & 0.33 & 4.34 & 3341 & 408.6 & & 81.7 & 70.6 & 245.5 & 227.6 & 388.1 & 5.1 \\
\hline
\end{tabular}

$$
\mathrm{Fe}^{2+}+\mathrm{S}_{5} \mathrm{~S}^{2-}+\mathrm{HS}^{-} \longrightarrow \mathrm{FeS}_{2}+\mathrm{S}_{4} \mathrm{~S}^{2-}+\mathrm{H}^{+}
$$

Kõik tänapäeval esitatud püriidi tekkereaktsioonide mehhanismid väidavad elementväävli sisseviimist raudsulfiidi molekuli. Vaatamata sellesuunalistele aktiivsetele uurimistöödele ei saa kaua tuntud ja laialt levinud mineraali - püriidi - tekkemehhanismi looduslikes protsessides, eriti nüüdisaegsetes meresetetes lõplikult lahendatuks lugeda $\left[^{8}\right]$, kuna paljusid püriidistumise aspekte pole selgitatud.

Tabel 2

Erinevate väävliliikide esinemisest Villandi-Laheküla leiukohtade diktüoneemakildas

\begin{tabular}{|c|c|c|c|c|c|}
\hline \multirow[b]{2}{*}{$\begin{array}{c}\text { Puuraugu } \\
\text { nr. }\end{array}$} & \multirow[b]{2}{*}{$\begin{array}{l}\text { Uld- } \\
\text { väävel }\end{array}$} & \multirow[b]{2}{*}{$\begin{array}{l}\text { Orgaaniline } \\
\text { väävel }\end{array}$} & \multirow{2}{*}{$\begin{array}{c}\text { Sulfaat- } \\
\text { väävel }\end{array}$} & \multicolumn{2}{|c|}{ Sulfiidväävel } \\
\hline & & & & $\begin{array}{l}\text { Metall- } \\
\text { sulfiid }\end{array}$ & $\begin{array}{l}\text { Püriit või } \\
\text { persulfiid }\end{array}$ \\
\hline 79 & 5.15 & 0.18 & 0.97 & 0.082 & 3.92 \\
\hline 93 & 3.55 & 0.22 & 0.87 & 0,066 & 2.39 \\
\hline 84 & 5.29 & 0.18 & 1.02 & 0.068 & 4.02 \\
\hline 99 & 4.61 & 0.29 & 0.63 & 0.072 & 3.66 \\
\hline 101 & 3.74 & 0.24 & 0.86 & 0.096 & 2.54 \\
\hline 103 & 4.38 & 0.26 & 0.86 & 0.079 & 3.18 \\
\hline 113 & 4.97 & 0.23 & 1.10 & 0.102 & 3.54 \\
\hline 107 & 1.99 & 0.15 & 0.74 & 0.097 & 1.00 \\
\hline 133 & 5.80 & 0.20 & 1.01 & 0.087 & 4.50 \\
\hline 119 & 4.88 & 0.13 & 0.95 & 0.098 & 3.70 \\
\hline 123 & 6.46 & 0.23 & 1.30 & 0.093 & 4.84 \\
\hline 131 & 4.02 & 0.18 & 1.05 & 0.104 & 2.69 \\
\hline ne & 4.57 & 0.20 & 0.95 & 0.087 & 3.33 \\
\hline
\end{tabular}

\section{Järeldused}

1. Villandi-Laheküla leiukohtade diktüoneemakilda kihi paksus lääne-ida suunas aheneb kuni 1.05 meetrini, põlemisväärtus on vähenenud $962.50 \mathrm{kcal} / \mathrm{kg}$, samuti orgaanilise aine sisaldus $11.48 \%$, püriitväävli sisaldus on tõusnud $3.33 \%$ (püriiti $7.18 \%$ ), ränidioksiidi ja teiste makrokomponentide $(\mathrm{Al}, \mathrm{K}, \mathrm{Ca}, \mathrm{Mg}, \mathrm{Fe})$ sisaldus on jäänud samasse suurus: 
jầrku, milles on läänepoolsete leiukohtade diktüoneemakilda makrokompónentide sisaldus.

2. Villandi-Laheküla leiukohtade diktüoneemakilda hajutatud ja haruldaste elementide sisalduse kohta võib öelda järgmist: läänest itta suundumisel suureneb $\mathrm{V}, \mathrm{Zn}, \mathrm{Mo}$, väheneb aga $\mathrm{Ti}, \mathrm{Cu}, \mathrm{Pb}$ sisaldus, peaaegu samaks jääb $\mathrm{Ni}$ ja In sisaldus.

3. Settekivimites laialt levinud mineraali - püriidi - ja temale vastava keemilise ühendi raudpersulfiidi tekkemehhanismide kohta pole olemas täit selgust.

\section{K I R J A N D S}

1. Kirret, O., Gerassimov, N., Tikk, A. Diktüoneema kiltkivi termilisest lagundamisest. Rmt.: Teaduslik-tehniline kogumik. 10. Tln., 1948, 47-59.

2. Киррет О. Г., Поликарпов Н. К., Луцковская Н. Л., Валдек Р. Г., Эйзен Ю. Н. О составе и свойствах диктионемового сланца месторождения Маарду ЭССР. Изв. АН ЭССР. Сер. техн. и физ.-матем. н., 1957, VI, № 2, 170-183.

3. Kirret, O., Koch, R., Ründal, L. Maardu leiukoha diktüoneemakilda ja temas sisalduva kerogeeni keemilisest koostisest. - ENSV TA Toim. Tehn. ja füüs.-matem. tead. seeria, 1959, VIII, nr. 4, 243-255.

4. Пелекис Л., Пелекис 3., Тауре Н., Киррет О., Раявее Э. Инструментальный нейтронно-активационный анализ диктионемового сланца Маардуского месторождения. - Изв. АН ЭССР. Хим., 1985, 34, № 3, $161-164$.

5. Kirret, O. Koch, R.| Rüidal, L., Johannes, I., Talkop, R.. Valkla-Tsitre ja Toolse diktüoneemakilda omadustest ja keemilisest koostisest. - ENSV TA Toim. Keem., 1986, 35, nr. 4, 237-244.

6. Гиллебранд В. Ф., Лендль Г. E. Практическое руководство по неорганическому анализу. М., 1957.

7. Пальмре $X$. Заметки о встречаемости индия в пиритовых кристаллах палеозойских отложений Эстонской ССР. —- Изв. АН ЭССР. Хим. Геол., 1976, 25, № 3, 245247.

8. Волков И. И. Океанология. Химия океана. 2. Геохимия донных осадков. М., 1979.

9. Сидоренко М. Петрографические данные по современным отложениям в Хаджибейском лимане и о литологическом составе поверхностных осадков Куяльницко-Хаджибейской пересыпи. - Зап. Новорос. о-ва естествоиспытателей, 24, вып. 1.

10. Doelter, C. Hydrotroilit. - Rmt.: Handb. Mineralchemie. 4. 1926.

11. Baas-Becking, L. Biological processes in the estuarine environment. VI. The state of the iron in the estuarine mud iron sulphides. - Proc. Kon. ned. acad. wetenssch., 1956, $\mathbf{5 9}$, N 3.

12. Волков Н. Н. О свободном сероводороде и сернистом железе в иловых отложениях Черного моря. - Докл. АН СССР, 1959, 126, № 1.

13. Волков Н. Н. Сульфиды железа, их взаимосвязь и превращения в осадках Черного моря. - Тр. ин-та океанологии АН СССР, 1961, 50,

14. Roberts, W. M. B., Walker, A. L., Buchmann, A. S. The chemistry of pyrite formation in aqueous solution and its relation to the depositional environment. - Miner. deposita, 1969, 4, N 1 .

Eesti NSV Teaduste Akadeemia Keemia Instituut

Toimetusse saabunud 10. X 1986

О. КИРРЕТ, $\overline{|Р . К О Х|}$, Л. РЮНДАЛ

\section{О СВОИСТВАХ И ХИМИЧЕСКОМ СОСТАВЕ ДИКТИОНЕМОВОГО СЛАНЦА МЕСТОРОЖДЕНИИ ВИЛЛАНДИ-ЛАХЕКЮЛА}

Опредслены средние значения теплотворности диктионемового сланца обоих месторождений и содержания в нем керогена, макро- и микрокомпонентов, а также элементов, присутствующих в виде следов.

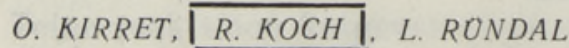

\section{CHEMICAL PROPERTIES AND COMPOSITION OF ALUM SHALE OF VILLANDI-LAHEKULA DEPOSITS}

The mean heat value, concentrations of kerogen, macro and micro components, and trace elemental composition of the above-mentioned deposits have been determined. 